\title{
Concurrent occurrence of vagino-cervical and rectal prolapse in a doe and its successful management
}

\author{
(D) S. Raja ${ }^{a}$, (D) P. Jayaganthan ${ }^{b}$, (D) V.Prabaharan ${ }^{a}$, (D) S. Satheshkumar
}

\begin{abstract}
assistant Professor, Department of Veterinary Gynaecology and Obstetrics, Veterinary College \& Research Institute, TANUVAS, Orathanadu - 614625.

${ }^{\mathrm{b}}$ Assistant Professor, Veterinary University Training and Research Centre, Thanjavur, TANUVAS, 613403

${ }^{c}$ Professor \& Head, Department of Veterinary Gynaecology and Obstetrics, Veterinary College \& Research Institute, TANUVAS, Orathanadu 614625.
\end{abstract}

Corresponding author: S. Raja | email: argoraja@gmail.com

Co-author: PJ: jayaganthanpv81@gmail.com; VP: kullupraba@gmail.com; SS: drsatheshkumar6@rediffmail.com

Received: 22-11-2020, Accepted: 12-12-2020, Published online: 24-12-2020

\begin{abstract}
Vaginal prolapse is a common reproductive problem during their last trimester of pregnancy. Protrusion of single or more layers of rectum through the anus is rectal prolapse. Rectal prolapse is also a common problem in cattle and small ruminants. Rectal prolapse occurs following straining which may be related with many conditions. In late gestation, vaginal prolapse may occur due to hormonal shift, decline in progesterone and rise in estrogen. Because of vaginal prolapse the animal may strain continually and end up with rectal prolapse and leads to a serious obstetrical emergency. A two and half years old pluriparous non descriptive doe was presented with the history of a mass protruding through the vulva and anal opening for the past five hours. Based on the initial clinical observation, the case was diagnosed as vagino-cervical prolapse coupled with rectal prolapse. The prolapsed vaginal mass and rectal mass was reduced and replaced in its anatomical position. Since the rectal straining was persistent, parturition was induced using cloprostenol $(125 \mu \mathrm{g})$ and dexamethasone sodium phosphate (16 $\mathrm{mg}$ ) as intramuscular injection. Following the induction, the doe delivered two live male kids after 36 hrs. After parturition straining was not observed. The animal made an uneventful recovery without any recurrence.
\end{abstract}

Keywords: Doe, Rectal Prolapse Vagino-cervical prolapse, Parturition, Induction

\footnotetext{
doi: https://doi.org/10.51128/jfas.2020.A025 | How to cite this article: Raja, S., Jayaganthan, P., Prabaharan, V. and Satheshkumar, S. 2020 Concurrent occurrence of vagino-cervical and rectal prolapse in a doe and its successful management. Journal of Food and Animal Sciences, 01 (02): 136 $-139$.

Copyright: Raja et al., 2020. Open Access. This article is distributed under the terms of the Creative Commons Attribution 4.0 International License (http://creativecommons.org/licenses/by/4.0/), which permits unrestricted use, distribution, and reproduction in any medium, provided you give appropriate credit to the original author(s) and the source, provide a link to the Creative Commons license, and indicate if changes were made. The Creative Commons Public Domain Dedication waiver (http://creativecommons.org/publicdomain/zero/1.0/) applies to the data made available in this article, unless otherwise stated.
} 


\section{Introduction}

Vaginal prolapse is defined as the eversion of a part or the whole vaginal wall with or without the cervix through the vulva (Youngquist, 2007). In cattle and sheep, vaginal prolapse is a common reproductive problem during their last trimester of pregnancy. However, it is rarely observed in goats (Kahn, 2005). Although vaginal prolapse occurs mainly in pregnant animals, the condition is also reported in non-pregnant ewes and heifers. In addition to that, postpartum vaginal and uterine prolapse has also been documented (Couri et al., 2012). The etiology of vaginal prolapse is multifactorial and can occur as a result of abnormal connective tissue, hereditary predisposition, nutritional, hormonal, and various other risk factors (Adams, 1990, Kahn, 2005, Sobiraj, 1990). Rectal prolapse is the protrusion of one or more layers of rectum through the anal opening. It can occur in all domestic animal species but commonly seen in pig, occasionally in cattle, and rarely in goat and other species (Rajesh et al., 2020; Sharun and Erdoğan, 2019). The present communication reports a rare occurrence of vaginal prolapse in combination with rectal prolapse in a non-descriptive doe.

\section{Case History and Observation}

A two and half years old pluriparous non descriptive doe was presented to the large animal Obstetrical unit of Veterinary College and Research Institute, Orathanadu with the history of a mass protruding from the vulva and anal opening for the past five hours. On general physical examination, the animal was found to be dull and depressed with rectal temperature of $102.4^{\circ} \mathrm{F}$. All other vital parameters were within the normal range. On clinical observation, the vagina and cervix were found to be protruded with intact cervical seal (Figure 1). In addition to that rectum was also got prolapsed (Figure 2). Intermittent intense straining could be observed. Edematous vulval lips along with relaxation of pelvic and sacrosciatic ligaments were also appreciated based on the clinical observation. The case was diagnosed as vaginocervical prolapse coupled with rectal prolapse with the animal nearing to parturition.

\section{Treatment}

Initially the animal was administered with $2 \%$ lignocaine hydrochloride @ $0.5 \mathrm{mg} / \mathrm{kg}$ as epidural anaesthesia to reduce the straining. Then the prolapsed mass of vagina was washed with potassium permanganate $(1: 1000)$ solution and examined for any laceration in the mucous membrane. The edema of the prolapsed mass was reduced by washing with hypertonic salt solution for ten minutes. The prolapsed mass was gently pushed back in to the pelvic cavity. Similarly, the prolapsed rectal mass was also washed with potassium permanganate (1:1000) solution and lubricated with liquid paraffin and replaced back in position. The animal was observed for 30 minutes for straining. Rectal straining was evident and no vaginal straining could be observed.

The animal was administered with gentamicin injection $(4.0 \mathrm{mg} / \mathrm{kg}, \mathrm{i} / \mathrm{m})$ for 4 days, dextrose normal saline (DNS), $150 \mathrm{ml} \mathrm{i/v;} \mathrm{and} \mathrm{calcium} \mathrm{gluconate,} 20$ $\mathrm{ml} \mathrm{i} / \mathrm{v}$ once. Since the dam is nearing parturition, it was decided to induce parturition using $125 \mu \mathrm{g}$ cloprostenol sodium via intramuscular route (Pragma ${ }^{\circledR}$, Intas Pharmaceuticals India) and dexamethasone sodium phosphate (Dexona ${ }^{\circledR}$ Vet, Zydus AH, India) $16 \mathrm{mg}$ intramuscularly. Since the rectal straining was persisting, purse string suture using cotton material was applied. After $36 \mathrm{hrs}$ following the interventions, the animal delivered two live male kids. After parturition straining was not observed. The animal made an uneventful recovery without any recurrence.

\section{Discussion}

The condition which causes severe straining may be associated with tenesmus (occurs with coccidiosis, proctitis, colitis etc.), dysuria (urethral obstruction, cystitis, urolithiasis, dystocia), neuropathy, chronic coughing or genetics, and increased intraabdominal pressure (Sastri, 2001). In case of advanced pregnancy, it may be associated with hypocalcemia (Radostits, 2009). In addition to that, other factors are conceded function of supporting tissue of pelvis, constipation, increased level of estrogen as in advance pregnancy, estrogenic feeds as growth promoter or access to estrogenic fungal toxin could play a major role in predisposing vaginal and rectal prolapse (Chakrabarti, 2004). In addition, the physiologic outcome of hypocalcemia are secondary bloat, ruminal stasis, constipation, relaxation of anus, and loss of anal reflex along with the atony of skeletal and smooth muscle. If the prolapse occurs in mid to late gestation, the pregnancy has to be maintained by simple vulval 
suture, Bhuners vulval retention suture or prolapse retainer. In the case of advanced pregnancy in goats, rectal prolapse may be ascribed to multiple fetuses and simultaneous hypocalcemia which can be managed by successful induction of pregnancy (Roberts, 1971).

\section{Authorship contribution statement}

S. Raja : Conceptualization, Methodology, WritingOriginal draft; P. Jayaganthan.: Validation; V. Prabaharan: Visualization, Investigation; S. Satheshkumar: Reviewing and Editing

\section{Acknowledgments}

The Authors acknowledge and thank Dean and Director of clinics for the facilities provided to conduct the study.

\section{Funding}

There is no substantial funding to be stated.

\section{Declaration of Competing Interest}

The authors declare that no conflict of interest for the study conducted.

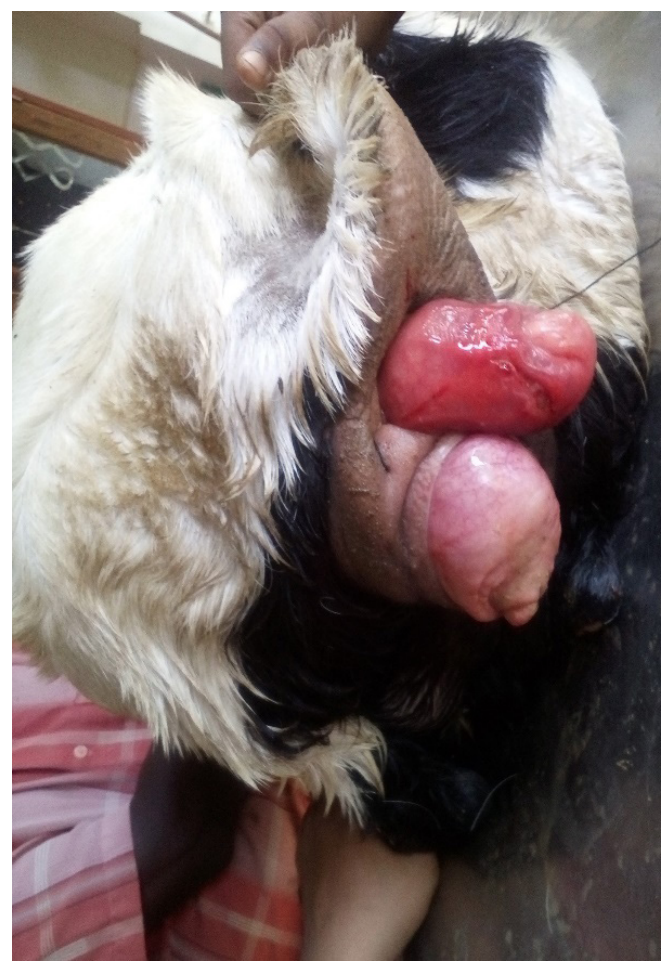

Figure 1: Vagino-cervical prolapse with concurrent rectal prolapse

\section{References}

Adams, N.R. 1990. Permanent infertility in ewes exposed to plant oestrogens. Australian Veterinary Journal, 67: 197.

Chakrabarti, A. 2004. Text Book of Clinical Veterinary Medicine. Kalyani Publishers, New Delhi, 233p.

Couri, B,M., Lenis, A.T., Borazjani, A., Paraiso, M.F.R. and Damaser, M.S. 201). Animal models of female pelvic organ prolapse: lessons learned. Expert Review of Obstetrics and Gynecology, 7 (3): 249-260. doi:10.1586/eog.12.24.

Kahn, C. 2005. Merck veterinary manual. (9 th Ed.) Rahway, NJ: Merck.

Radostits, O.M., Gay, C.C., Hinchcliff, K.W., Constable, P.D. 2009. Veterinary Medicine A textbook of the diseases of cattle, horses, sheep, pigs and goats. $\left(10^{\text {th }}\right.$ Ed). W.B. Saunders Company, 279 p.

Rajesh Kumar, Diwakar, Ramakant. RP., Safayat Husain and Kabir Alam. 2020. A rare case of antepartum rectal prolapse in a goat and its management: A case report. Journal of Entomology and Zoology Studies. 8(2): 1285-1287

Roberts, S.J. 1971. Veterinary Obstetrics and Genital Diseases, $\left(2^{\text {nd }} E d\right)$. CBS Publisher \& Distributors

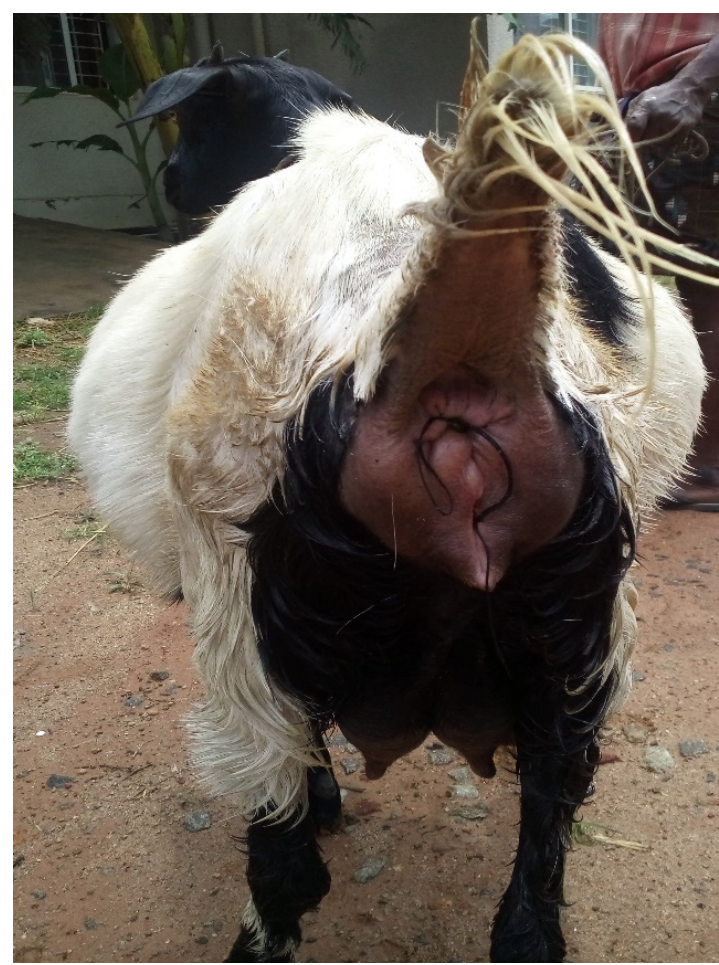

Figure 2: After the reduction of prolapse and purse string suture 


\section{Pvt Ltd, New Delhi, 307p.}

Sastri, G.A. and Rama Rao, P. 2001. Veterinary Pathology. CBS Publisher \& Distributors Pvt Ltd, New Delhi, 352p

Sharun, K., and Erdoğan, G. 2019. A Review: Obstetrical Emergencies in Small Ruminants. Alexandria Journal for Veterinary Sciences, 62(1): $1-16$.
Sobiraj, A. 1990. Ante partum vaginal prolapse in sheep - an unsolved problem. Tierarztl. Prax (Full article in German with English abstract), 18 (1): 9-12. [PubMed: 2183394]

Youngquist, R.S and Threlfall, W.R. 2007. Current Therapy in Theriogenology. (II $\left.{ }^{\text {nd }} E d\right)$. Saunders and Co., Philadelphia, U.S.A. 914 p 